\title{
Multi-Train Energy Saving for Maximum Usage of Regenerative Energy by Dwell Time Optimization in Urban Rail Transit Using Genetic Algorithm
}

\author{
Fei Lin *, Shihui Liu, Zhihong Yang, Yingying Zhao, Zhongping Yang and Hu Sun \\ School of Electrical Engineering, Beijing Jiaotong University, No. 3 Shangyuancun, Beijing 100044, China; \\ 14121430@bjtu.edu.cn (S.L.); 15121496@bjtu.edu.cn (Z.Y.); 12121591@bjtu.edu.cn (Y.Z.); \\ zhpyang@bjtu.edu.cn (Z.Y.); hsun1@bjtu.edu.cn (H.S.) \\ * Correspondence: flin@bjtu.edu.cn; Tel.: +86-136-4139-8863
}

Academic Editor: William Holderbaum

Received: 2 February 2016; Accepted: 10 March 2016; Published: 17 March 2016

\begin{abstract}
With its large capacity, the total urban rail transit energy consumption is very high; thus, energy saving operations are quite meaningful. The effective use of regenerative braking energy is the mainstream method for improving the efficiency of energy saving. This paper examines the optimization of train dwell time and builds a multiple train operation model for energy conservation of a power supply system. By changing the dwell time, the braking energy can be absorbed and utilized by other traction trains as efficiently as possible. The application of genetic algorithms is proposed for the optimization, based on the current schedule. Next, to validate the correctness and effectiveness of the optimization, a real case is studied. Actual data from the Beijing subway Yizhuang Line are employed to perform the simulation, and the results indicate that the optimization method of the dwell time is effective.
\end{abstract}

Keywords: genetic algorithm; dwell time; energy saving; braking energy; multi-train; urban rail transit

\section{Introduction}

Urban rail transit is an important part of urban public transport. With the characteristics of large capacity, high speed, security, punctuality, environmental protection, energy saving, and so on, urban rail transit is very popular and is especially suitable for large- and medium-sized cities [1]. China is the most populous country in the world and is very suitable for the development of urban rail transit. The first subway line in China was constructed in Beijing. Its planning began in 1953; the project was founded in 1965 and completed in 1969; and operations began in 1971. Today, the Beijing urban rail transit system is the second largest city subway system in the world. According to statistics from Beijing Subway, in the first three days of 2016, 16,367,700 passengers were transported, and 16,567 trains ran according to plan. In 2015,2,832,000,000 passengers were transported, and a total of 2,324,486 trains ran according to plan [2]. Energy consumption of urban rail transit is much lower than buses or cars per passenger per $\mathrm{km}$. However, the energy consumption of urban rail transit has a considerable scale with a large capacity. How to effectively reduce this energy consumption is a very significant matter.

González-Gil [3] provided a comprehensive appraisal of the main practices, strategies and technologies currently available for minimizing the energy use of urban rail systems. The two main methods are energy-efficient driving and regenerative braking. The former has been well studied by many researchers [4-7], while the latter is a rather new approach [8-10]. The braking system of subway trains typically adopts regenerative braking as the main system and air brakes (friction brakes) as a supplement. When the vehicle uses regenerative braking, the motor works in the state of the generator, 
and the electric energy generated returns to the traction power grid. In an urban rail transit system, the distance between stations is relatively short; thus, the train must perform frequent starting and braking, and this aspect of the braking energy has a great potential for recycling. The regenerative braking energy can reach up to more than $30 \%$ of the traction energy. If the regenerative braking energy cannot be used, then it is converted to a resistance brake or air brake, and the braking energy is wasted in vain. The energy that is not used accounts for more than $40 \%$ of the total braking energy used.

At present, the effective utilization of regenerative braking energy involves two main aspects of research [9]. One is using energy storage devices, such as flywheels [11-14], supercapacitors [15-21] and batteries [22-25]. New infrastructure requires a large amount of investment and is not easy to realize. The other method is operation optimization, which is more convenient. This method has also been studied by some researchers. Chen [26] optimized the timetable to reduce the maximum traction power. Kim et al. $[27,28]$ developed a mixed integer programming model to minimize the maximum traction energy, which occurs when trains are running simultaneously. Gordeon [29] coordinated multi-trains to reduce the total traction energy. Ramos [30] coordinated a train's acceleration and braking time to make full use of renewable energy. Yang et al. [31] increased the traction and braking overlap rate of different trains to optimize the timetable, thereby improving the utilization efficiency of regenerative braking. Zhao et al. [32] optimized schedules using the simulated annealing algorithm, by analyzing the relative position and running state of the adjacent train. The above researchers did not consider the effect of the traction power supply network. The following research considers the traction network model. Nasri et al. [33] optimized a timetable for maximum usage of regenerative braking energy and discussed the headway and stop time effect on the energy consumption. Albrecht et al. [34,35] researched the headway and stop time effect on the energy consumption based on a route in Berlin. In addition, there has also been other research with different parameter optimizations and methods [36-38].

In the present paper, the train dwell time is optimized to achieve the purpose of the use of regenerative braking energy. This paper is arranged as follows: Section 2 outlines the overall situation. A multi-train system for urban rail transit is introduced. The constraint conditions of multi-train operation optimization, considering regenerative braking energy, are analyzed. The principle of dwell time optimization is introduced. In Section 3, a train operation model and tractive power supply system model are established. The optimization goals of multi-train energy saving operation are settled. The calculation flow of multi-train operation is proposed. In Section 4, the genetic algorithm optimization is described. A mathematical model is established, and the genetic algorithm is introduced briefly. The optimization method and calculation flowchart are proposed. Finally, the actual train data, line data and power supply system data of the Beijing Yizhuang subway line are employed for simulation, and the performance of the simulation system is tested.

\section{Multi-Train System for Urban Rail Transit}

\subsection{Multi-Train System for Urban Rail Transit}

The multi-train operation optimization is based on the single-train operation model. The calculation of the operation of each train is constrained by the traction braking characteristics of the vehicle and line condition. Vehicle characteristics include traction performance of the vehicle, braking performance, performance of the train running resistance, vehicle formation, weight of the vehicle itself and load, etc. Line conditions include the ramp of the line, curve, speed limit, station spacing, etc. For multiple trains operating on the same route, the line conditions of a train running on the same line (uplink or downlink) are the same, and vehicle characteristics are generally the same, while the load of each train varies with the passenger flow.

The traction substation in the traction power supply system transfers the three-phase high voltage alternating current (AC) into low voltage direct current (DC) used by urban rail trains. The DC-side power supply system is the part of the whole traction power supply system that directly provides 
power for the train. It mainly includes the catenary (three rail), the feeder line, the track and the reflux line. The feeder line delivers direct current from the traction substation to the catenary; the train obtains the electric energy through the direct contact of the current collector (pantograph or collector shoe) and the catenary; and the drive traction motor causes the train to operate. The track not only has the function of a guide rail, but also that of conduction reflux, leading the reflux from the track into the traction substation through the reflux line, as shown in Figure 1.

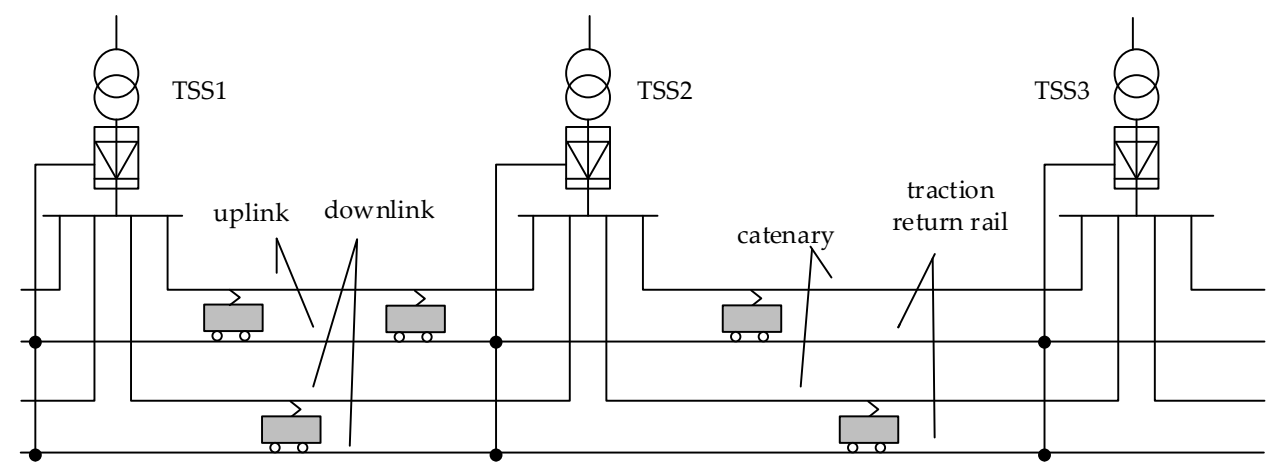

Figure 1. Schematic diagram of the urban rail transit power supply system. TSS, traction substation.

\subsection{The Constraints of the Traction Power Supply System}

The constraints of the traction power supply system when the train is operating are mainly as follows [39]:

1. For urban rail transit traction power supply systems, due to the fact that the DC traction substation adopts the diode rectifier, the energy has unidirectional liquidity, and regenerative braking energy cannot flow from the substation to the power supply network.

2. Feeder loss. Due to the resistance of the traction network, line loss is inevitable, and the line resistance changes with the change of the train operation position.

3. The train's traction and regenerative braking curve are constrained by the traction network voltage, as shown in Figure 2, and the drop of traction network voltage, train tractive and regenerative braking capacity will be limited.
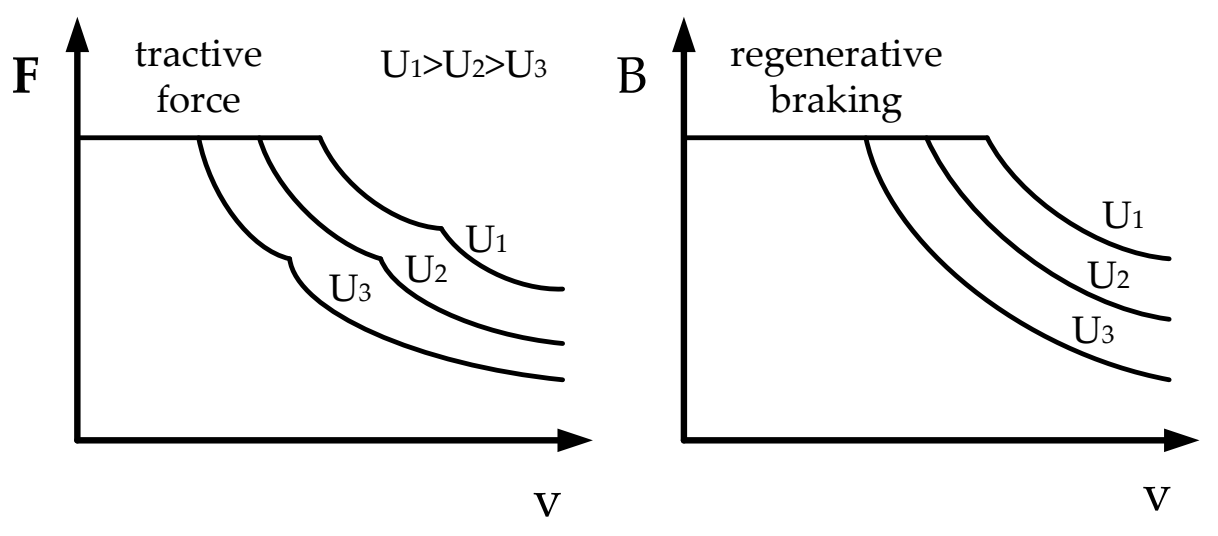

Figure 2. Tractive and regenerative braking curve under different net voltages.

4. The regenerative braking is restricted by the traction network voltage. With the increase of traction network voltage, the regenerative braking power is limited. As shown in Figure 3, when the network voltage rises to $\mathrm{U} 1$, the train limit motor current reduces the output of the regenerative braking power; when the network voltage reaches the maximum limit voltage U2, then the regenerative braking is removed, and the motor current is zero. 


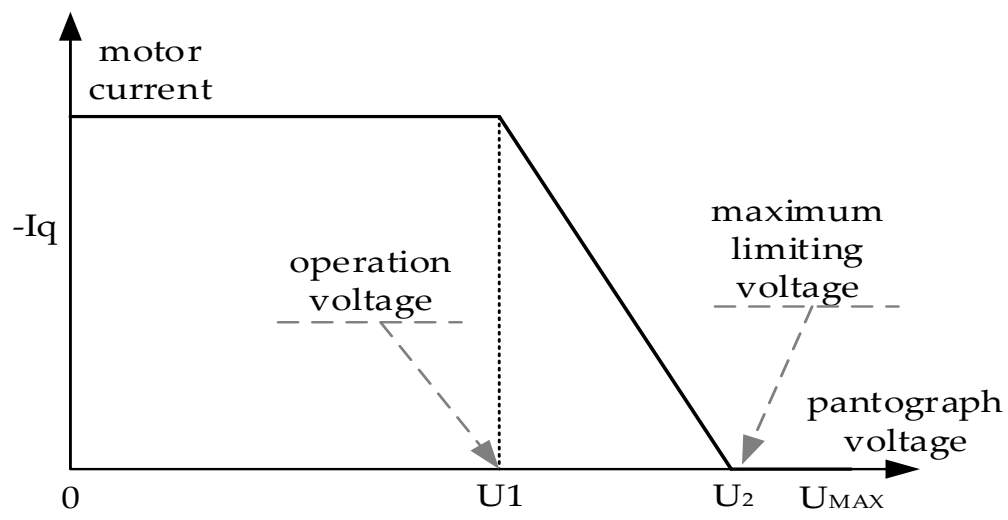

Figure 3. Squeezing curve of regenerative braking.

5. If there are energy storage devices (such as a super capacitor) in the line, they will affect the charging state of the energy storage device. For multi-train operation, to accurately calculate the energy consumption of the system and the utilization of the regenerative braking energy, a complete simulation model of the train and traction power supply system is required. The model of the traction power supply system includes the model of the substation, the model of the rectifier unit, the resistance model of the line, the model of the train, the model of the braking resistance, etc.

\subsection{Principles of Dwell Time Optimization}

Urban rail transit system station spacing is relatively short, usually $1.5-2 \mathrm{~km}$; thus, it must be able to quickly start or stop; the train's traction acceleration is generally $0.9-1.0 \mathrm{~m} / \mathrm{s}^{2}$, and braking deceleration is about $1.0 \mathrm{~m} / \mathrm{s}^{2}$. Taking the Yizhuang Line as an example, it takes about $39 \mathrm{~s}$ to accelerate to $80 \mathrm{~km} / \mathrm{h}$; the maximum power needed for traction is about $3.6 \mathrm{MW}$; and traction energy consumption is $28 \mathrm{~kW}$. h. It takes about $27 \mathrm{~s}$ from the speed of $80 \mathrm{~km} / \mathrm{h}$ to stop, the maximum power of regenerative braking is approximately $3.6 \mathrm{MW}$; the produced regenerative braking energy is about $16 \mathrm{~kW} \cdot \mathrm{h}$; and train dwell time in the stop is generally $30-35 \mathrm{~s}$. A reasonable adjustment of the dwell time can improve the possibility that traction conditions and braking conditions occur at the same time with different trains, thus allowing the traction train to absorb greater regenerative braking energy and improve the regenerative braking energy utilization rate of the train.

Figures 4 and 5 are the power curves of two trains running in the same power range, and the blue and red curves represent Train 1 and Train 2, respectively. Train 2 starts $50 \mathrm{~s}$ after Train 1 . The two train power curves are the same. In Figure 4, Train 2 operates at the first station. At 118-135 s, then the traction and braking of Train 1 and Train 2 overlap, and Train 1 can use the regenerative braking energy of Train 2; at 179 198 s, Train 2's traction condition and Train 1's braking condition overlap, and the regenerative braking energy of Train 1 is partly used by Train 2; at $210 \mathrm{~s}$ and later, Train 1 stops, Train 2 brakes, and the regenerative braking energy of Train 2 cannot be used. In Figure 5, the dwell time of Train 2 is extended, and the starting time of Train 2 in the second station is delayed. It can be seen that, compared to Figure 4, in Figure 5, the train operating condition overlapping time is extended from 179 198 s to 179 205 s, and Train 2 uses more regenerative braking energy from Train 1, while the overlapping time of one train's traction condition and another train's braking condition is added to the $235 \sim 260 \mathrm{~s}$. From Figures 4 and 5 it can be seen that the adjustment of the stop time has a great impact on the regenerative braking energy.

Therefore, based on the existing schedule, reasonably adjusting the stop time of the train can effectively increase the overlapping time of the train traction and braking, so that more regenerative braking energy is utilized by the traction train nearby, thereby improving the utilization efficiency of regenerative braking energy and reducing the system total energy consumption. 


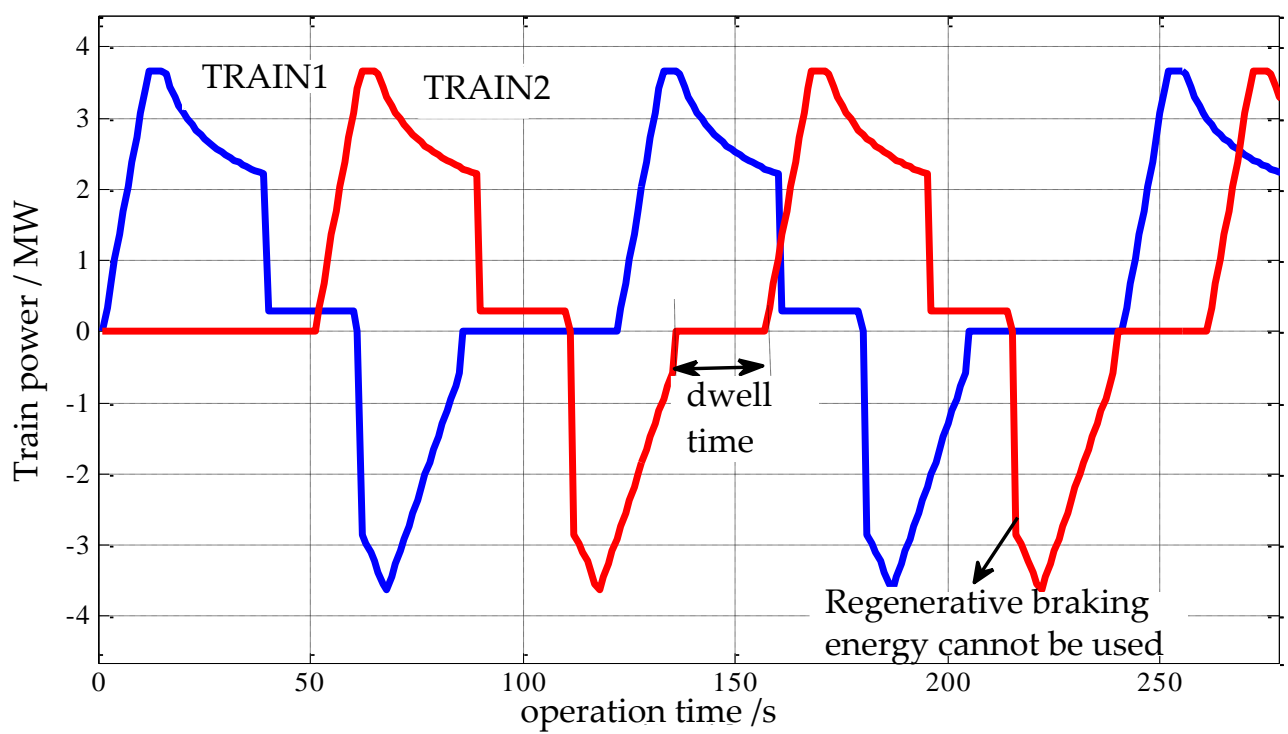

Figure 4. Train power curves before dwell time modification.

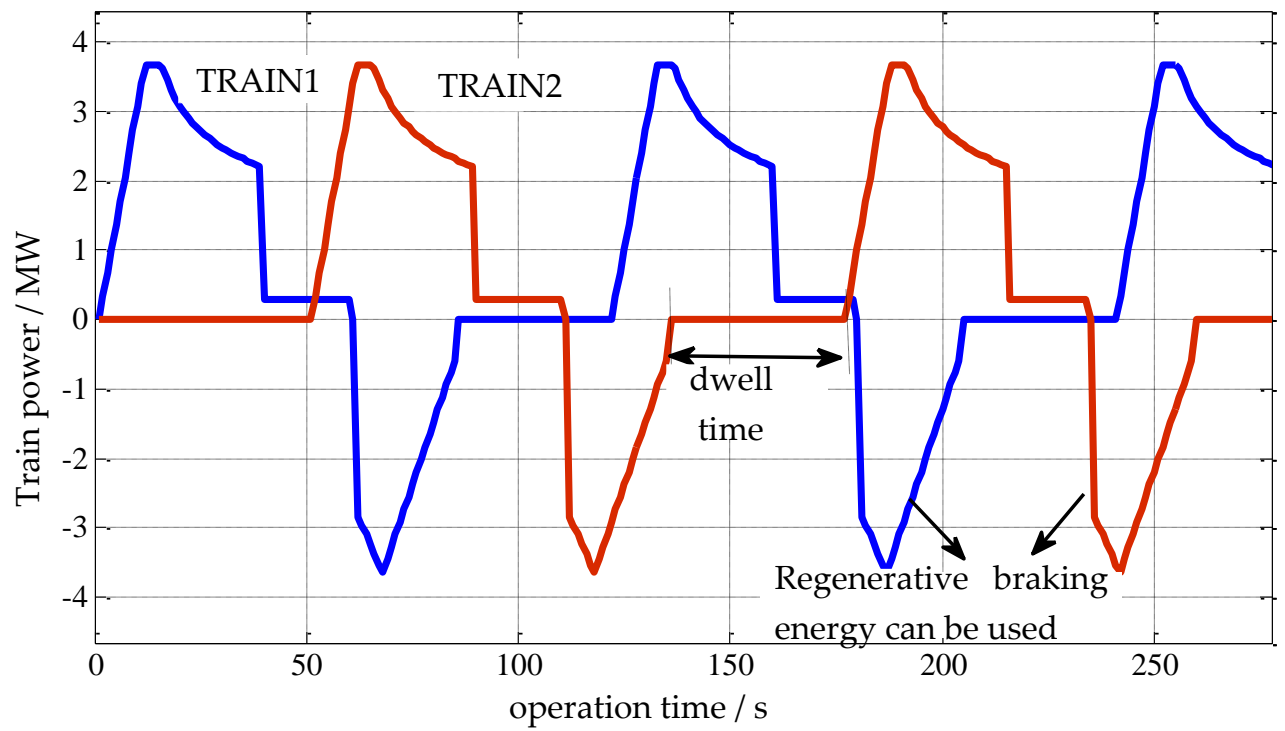

Figure 5. Train power curves after dwell time modification.

\section{Train Operation and Power Supply System Modeling}

\subsection{Train Operation Model}

A multi-train operation model is established based on the single-train operation model, in which the train operation state equation and the constraint conditions that need to be satisfied, such as the dynamic performance of the train and the line conditions, are the same, but the traction network voltage constraints on the operation of the train are added. Assuming that there are $N$ trains on the line, for train $j$, the train operation model must meet the following conditions:

Train kinematics model:

$$
\dot{x}_{j}=\left\{\begin{array}{cc}
v_{j} & \left(t_{j 0} \leqslant t \leqslant t_{j f}\right) \\
0 & \left(t s_{j 0} \leqslant t \leqslant t s_{j f}\right)
\end{array}\right.
$$




$$
\dot{v}_{j}=\left\{\begin{array}{lr}
f_{j}\left(u_{j}, U_{T j}, v_{j}\right)-r_{j}\left(x_{j}, v_{j}\right) & \left(t_{j 0} \leqslant t \leqslant t_{j f}\right) \\
0 & \left(t s_{j 0} \leqslant t \leqslant t s_{j f}\right)
\end{array}\right.
$$

where $x_{j}$ is the position of train $j$ at $t$ time; $v_{j}$ is the speed of train $j$ at $t$ time; $u_{j}$ is the traction or braking control parameters of train $j ; U_{T j}$ is the pantograph voltage of train $j ; f_{j}$ is the unit mass tractive force or braking force with current control parameters $f_{j}$, voltage $U_{T j}$ and speed $v_{j} ; r_{j}$ is the sum of the running resistance and accessories resistance of the unit mass of train $j$ in the current position $x_{j}$ with speed $v_{j}$; $t_{j 0}$ is the starting time of train $j ; t_{j f}$ is the dwell time of train $j ; t s_{j 0}$ is the start moment of the dwell time of train $j$; and $t s_{j f}$ is the end moment of the dwell time of train $j$.

Beginning and end state constraints of the train:

$$
\begin{gathered}
x\left(t_{j 0}\right)=x_{j 0}, \quad v\left(t_{j 0}\right)=0 \\
x\left(t_{j f}\right)=x_{j f}, \quad v\left(t_{j f}\right)=0 \\
x(t)=x_{j f}, \quad v(t)=0 \quad\left(t s_{j 0} \leqslant t \leqslant t s_{j f}\right)
\end{gathered}
$$

Train dynamic performance constraint:

$$
-1 \leqslant u_{j} \leqslant 1
$$

Figure 6 is the schematic diagram of $u_{j}$, where, when the value of $u_{j}$ is greater than zero, $f_{j}$ is positive, as the traction force; when the value of $u_{j}$ is less than zero, then $f_{j}$ is negative, as is the braking force; when the value of $u_{j}$ is zero, then $f_{j}$ is zero, and the train is in the coasting drifting condition, as shown in Equation (7).

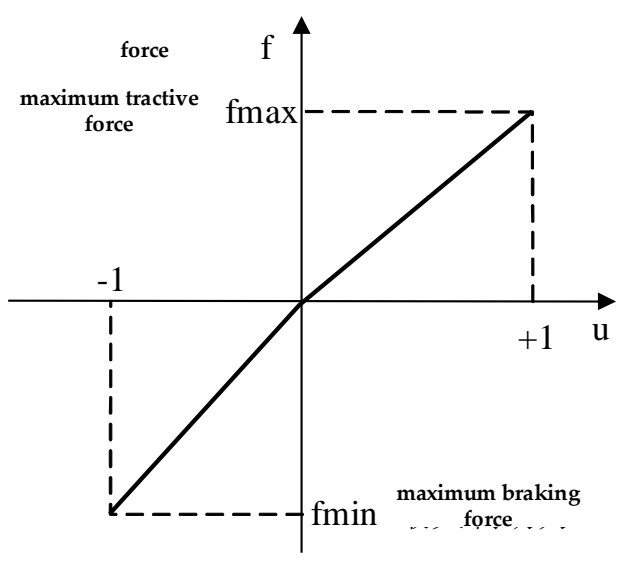

Figure 6. Definition of control parameter $u$.

According to Equation (6) and the relationship between traction force and network voltage (Figure 2), the relationship among train force $f_{j}$ (traction or braking force), control parameters $u_{j}$, network voltage $U_{T j}$ and train speed $v_{j}$ can be obtained, as shown in Equation (7):

$$
f_{j}\left(u_{j}, V_{T j}, v_{j}\right)= \begin{cases}u_{j} \cdot f_{j \max }\left(U_{T j}, v_{j}\right) & \left(u_{j} \geqslant 0\right) \\ u_{j} \cdot f_{j \min }\left(U_{T j}, v_{j}\right) & \left(u_{j}<0\right)\end{cases}
$$

where $f_{\text {jmax }}$ is the maximum traction force of train $j$ with the current speed $v_{j}$ and voltage $U_{T j}$; and $f_{j m i n}$ is the maximum braking force of train $j$ with the current speed $v_{j}$ and voltage $U_{T j}$. 
Line speed limit constraint:

$$
0 \leqslant v_{j} \leqslant V_{\text {max }}\left(x_{j}\right)
$$

where $V_{\text {jmax }}$ is the maximum speed allowed of train $j$ in the current location $x_{j}$.

\subsection{Traction Power Supply System Model}

In a multi-train operation process, power taken from the catenary and position of every train is constantly changing. In terms of circuit theory, the traction power supply system is a complex time-varying network; the power supply system state is related to location $x(t)$, speed $v(t)$, pantograph voltage $U(t)$ and train control parameters $u(t)$ of each train, as well as the number of circuit equations and the train number and locations.

With a normal bilateral power supply, the traction substation bus link uplink and downlink catenary (third rail) and, similarly, uplink and downlink rail are linked through the return line. The substations of the traction network all contribute. Due to the parallel operation of the uplink and downlink trains, it is necessary to consider the interaction between the upper and lower catenary and track when establishing the mathematical model of the DC side [40].

\subsubsection{Power Substation Model with Rectifier Units}

The external characteristic of the rectifier unit is that the DC output voltage curve changes with the load current or short-circuit current. The rectifier unit in the DC traction power supply system simulation is often treated as a constant ideal voltage source with internal resistance, as shown in Figure 7.

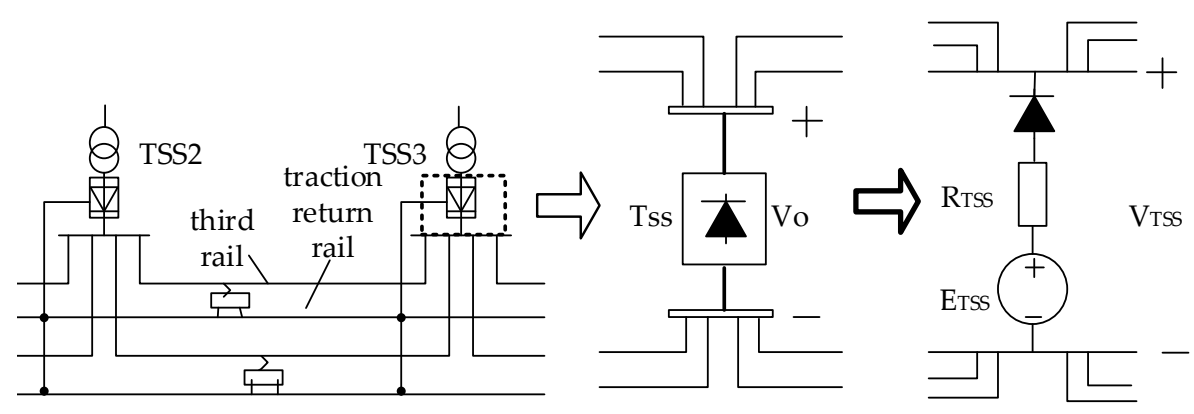

Figure 7. Schematic diagram of rectifier units.

The TSS is the traction substation; $\mathrm{R}_{\mathrm{TSS}}$ is the substation equivalent resistance; $\mathrm{E}_{\mathrm{TSS}}$ is the equivalent voltage source of the substation; and $V_{\text {TSS }}$ is the substation busbar voltage. In fact, the external characteristic of the rectifier unit is nonlinear. In this paper, the output characteristic curve of the two parallel 12-pulse rectifier circuits is equivalent to the external characteristic curve of the 24-pulse rectifier circuit, and the substation external characteristic curve adopts the multi-linear model proposed in [41].

\subsubsection{Train Model}

The train power taken from the network is often dependent of the network voltage, and the current is greatly influenced by the network voltage; thus, the power source model is used for the train model in the traction power supply system. The speed, position and power of each train at each moment can be obtained using the train operation model. As the train is based on the power source model, the circuit equations are a nonlinear equation set and must be solved using the iterative method. When train traction occurs, the power value is positive, which means that electrical power must be obtained from the DC net; when the train is coasting, the power used is train auxiliary power obtained 
from the DC net power; and during regenerative braking, the power is negative, which means that regenerative braking power flows from the train to the power grid [42].

\subsubsection{Traction Network Model}

The line resistance of the traction network changes with the change of the location of the train and the position between trains, which mainly includes the line resistance between the train and the substation, the line resistance between trains and the leakage resistance of the track to the ground. The leakage resistance is generated due to the fact that the most traction current flows back to the traction substation along the rail line, as part of it leaks into the ground, then flows back to the rail and then back to the traction substation. When calculating the equivalent resistance, it is necessary to consider the leakage resistance. According to the uniform transmission line theory, the accurate equivalent $\pi$ circuits $[43,44]$ are used for each section of the line tracks. Considering the precision of the modeling, the upper and lower rails should be modeled separately, as shown in Figure 8.

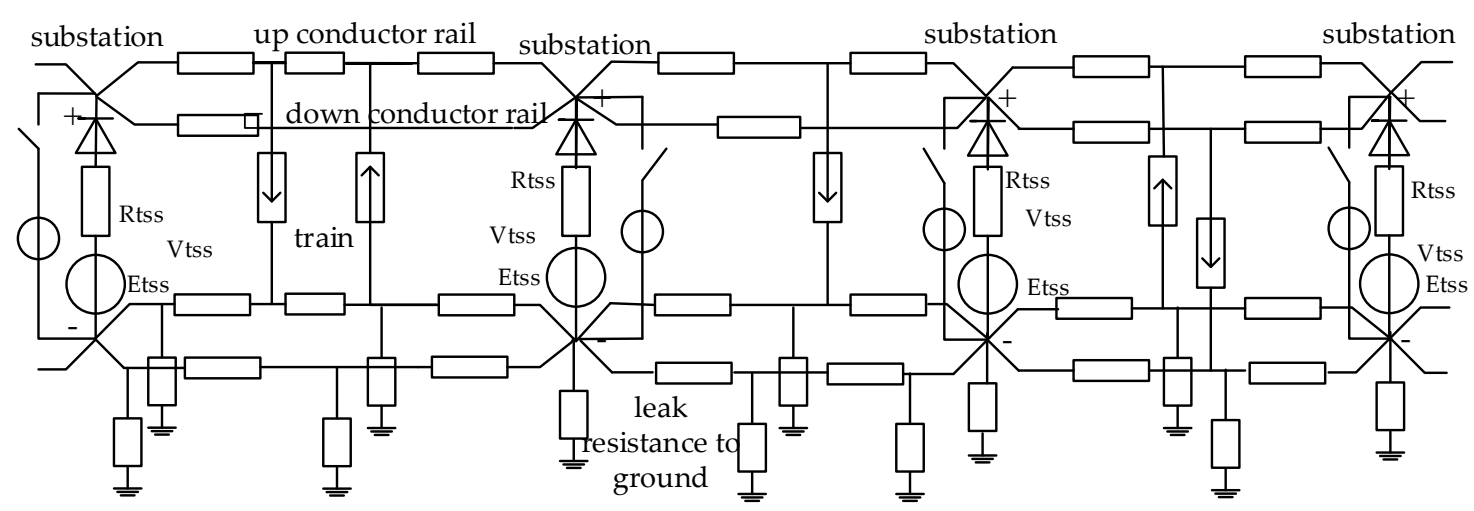

Figure 8. Equivalent circuit of the DC power supply system.

\subsection{Optimization Goal of Multi-Train Energy Saving Operation}

\subsubsection{Calculation of Energy Consumption Parameters}

According to the circuit solution of the traction power supply system, the dynamic electrical data, such as voltage, current of each train and substation, can be obtained, and according to the voltage and current integral, the train and substation's energy consumption values can be obtained.

When the train current is positive, it is in the traction state, and the power integration of the corresponding time is the train traction energy consumption.

$$
E_{\text {tra }}=\int_{0}^{T} P_{\text {tra }} d t=\int_{0}^{T} I_{\text {tra }} \cdot U_{\text {train }} d t
$$

where $P_{t r a}$ is the train traction power; $I_{t r a}$ is the train traction current; $U_{t r a i n}$ is the train pantograph voltage; and $T$ is the total running time.

When the train current is negative, it is in the regenerative braking state, and the power integration of the corresponding time is the train regenerative braking energy.

$$
E_{\text {reg }}=\int_{0}^{T} P_{\text {reg }} d t=\int_{0}^{T} I_{\text {reg }} \cdot U_{\text {train }} d t
$$

where $P_{\text {rega }}$ is the train regenerative braking power; and $I_{\text {reg }}$ is the train regenerative braking current. 
According to the calculated results of the substation, the power integration at the time substation current is positive, which means that the output energy is the substation traction energy consumption within the corresponding time.

$$
E_{\mathrm{sS}}=\int_{0}^{T} P_{s s} d t=\int_{0}^{T} U_{s} \cdot I_{s} d t
$$

where $E_{S S}$ is the substation energy consumption; $P_{S S}$ is the substation power; $U_{S}$ is the substation voltage; and $I_{S}$ is the substation current.

In this paper, the model of the braking resistor is added to the actual simulation to calculate the unemployed regenerative braking energy. The braking resistance absorption power integration is the regenerative braking energy, which is not being used at the running time.

$$
E_{\text {reg_unuse }}=\int_{0}^{T} P_{b r \_r e s} d t=\int_{0}^{T} U_{s} \cdot I_{b r \_r e s} d t
$$

where $E_{\text {reg_unused }}$ is the braking resistance absorption energy; $P_{b r \_r e s}$ is the braking resistance absorption power; and $I_{b r_{-} r e s}$ is the braking resistance absorption current.

\subsubsection{Optimization Goal of Multi-Train Operation}

When operating multi-trains, considering the utilization of regenerative braking energy, the energy consumption of the system consists of the following:

$$
\begin{gathered}
\sum E_{\mathrm{ss}}=\sum E_{\text {tra }}-\sum E_{\text {reg_used }}+\sum E_{\text {loss }} \\
\sum E_{\text {reg_used }}=\sum E_{\text {reg }}-\sum E_{\text {reg_unuse }}
\end{gathered}
$$

where $\sum E_{S S}$ is the total energy consumption of all substations; $\sum E_{\text {tra }}$ is the total traction energy consumption of all trains; $\sum E_{\text {reg_used }}$ is the system total used regenerative braking energy; $\sum E_{\text {loss }}$ is the total traction power supply network line loss; $\sum E_{\text {reg_unuse }}$ is the system total unused regenerative braking energy; and $\sum E_{\text {reg }}$ is the total regenerative braking energy of all trains.

As can be seen, the effective use of multi-train regenerative braking energy can reduce the system's total substation energy consumption. The multi-train operation optimization aims to optimize the substation total energy consumption, as shown in Equation (15).

$$
J=\sum_{S=1}^{M} E_{s S}
$$

where $J$ is the substation total energy consumption; and $M$ is the number of traction substations.

To more accurately measure the use of the regenerative braking energy before and after optimization, we define the regenerative braking energy utilization, namely the ratios of total regenerative braking energy used by the trains and total regenerative braking energy generated by the trains, as shown in Equation (16):

$$
\eta_{\text {reg-used }}=\frac{\sum E_{\text {reg }}-\sum E_{\text {reg_unuse }}}{\sum E_{\text {reg }}} \times 100 \%
$$

where $\eta_{\text {reg-used }}$ is the regenerative braking energy utilization.

\subsection{Calculation Flow of Multi-Train Operation}

\subsubsection{Calculation of Train Operation}

In this paper, the discussion of multi-train operation is built on the assumption that each of the trains is strictly restrained by schedule, and the models are simplified: the former means assuming the 
operation curves of each train running in the same direction are the same; and the latter means not considering the effect of traction network voltage to train traction and braking performance, assuming that the current network voltage can meet the needs of the train traction and braking performance.

As shown in Figure 9, dwell time, running time, train date and line data are the input data of single train operation calculation. Additionally, the time-power curve and the time-distance curve obtained by single-train operation calculation are the input data of multi-train operation simulation.

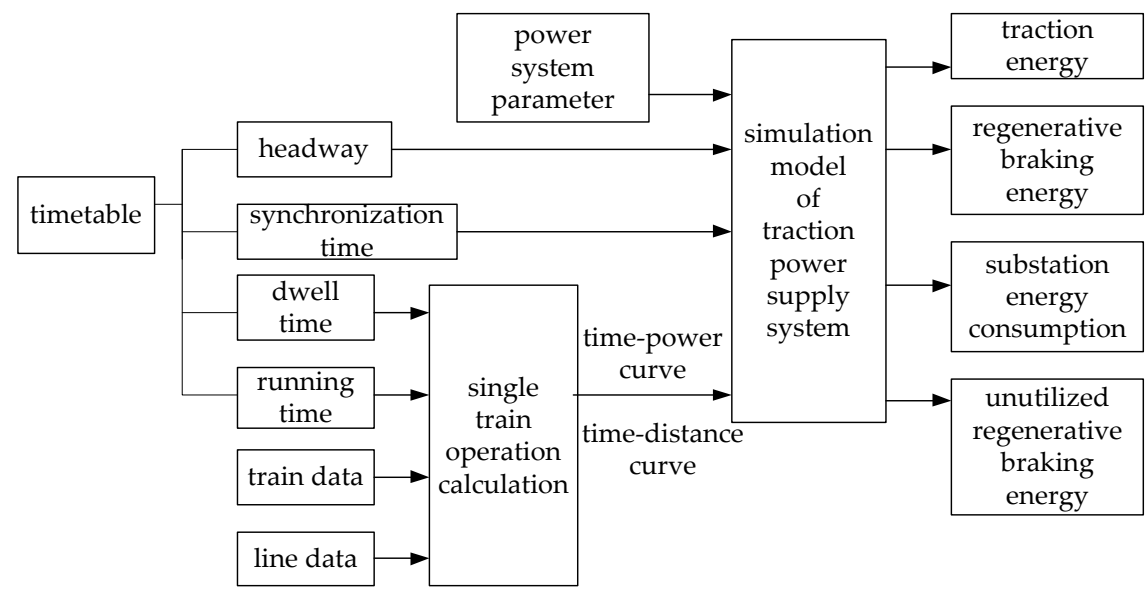

Figure 9. Flowchart of multiple train operation calculation.

\subsubsection{Multi-Train Operation Simulation}

First, the simulation model of the traction power supply system is built according to the actual parameters of the line. Via the position, power and other information of the uplink and downlink trains at each moment obtained by single-train running calculation, and based on the constraint of headway and synchronization time according to the schedule, the time, position and power of multiple train operation are obtained, to be used as the input of the traction power supply system simulation model. As shown in Figure 9, according to the input multi-train operation data, the structure current traction network equivalent circuit in the model of the traction power supply system, we can determine the electrical parameters of the traction network and obtain the total traction energy consumption and regenerative braking energy of the multi-train operation, as well as the total energy consumption and unused regenerative braking energy of the traction power system in a given period of time.

\subsubsection{Overall Process of Calculation}

Based on MATLAB, this paper next carries out the programming of the multi-train operation simulation model, and the basic framework and data structure of the model are shown in Figure 9. Figure 9 is the summary of the content of Sections 3.4.1 and 3.4.2.

\section{Genetic Algorithm Optimization}

Based on the mathematical model of the multi-train operation established above, the dwell time influence on the regenerative braking energy utilization and total energy consumption of the system is researched. The energy consumption model based on the dwell time is established and is optimized with genetic algorithms. Simulation and verification are performed based on the actual data of the Yizhuang Line.

\subsection{Mathematical Model}

The research of the dwell time is based on the assumption that the headway, synchronization time and inter-station travel time are all fixed. 
Figure 10 is the schematic diagram of the dwell time modification. Assuming that the number of stations in the line is $N$, then the dwell time at each station of the line are: $t_{1}, t_{2}, \ldots, t_{N}$, where $t_{N}$ is the dwell time at the $\mathrm{N}$-th station. The total energy consumption of the system is different with different dwell time combinations; thus, the problem can be abstracted as a combinatorial optimization problem of dwell time and energy consumption, such as shown in Equations (17) and (18).

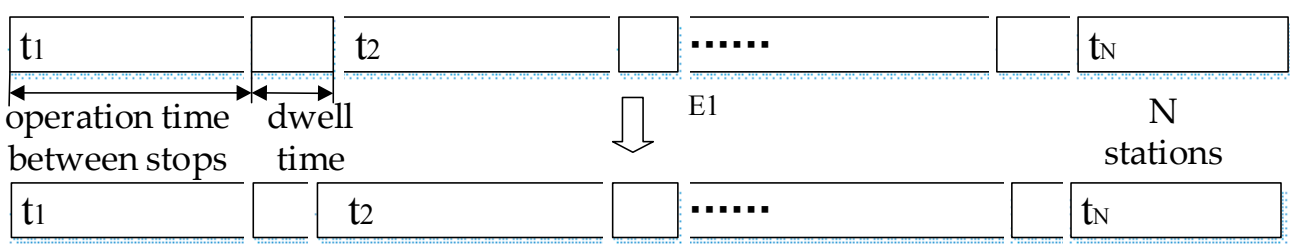

E2

Figure 10. Schematic diagram of dwell time modification.

For $N$ stations, assuming that the dwell time of train, $t_{\text {stop }}$, has $k$ combinations, then $t_{\text {stop } \_} i$ is the $i$-th dwell time combination.

$$
t_{\text {stop_ } i}=\left\{t_{1}, t_{2}, \cdots t_{i} \cdots, t_{N-1}, t_{N}\right\}
$$

$k$ combinations of dwell time have corresponding system total consumption $E_{i}$ :

$$
E_{i}=f\left(t_{\text {stop_i } i}\right)
$$

For urban rail transit, there are typically 10-15 stations. Assuming that the dwell time of each station is adjusted by $-5 \mathrm{~s}-+5 \mathrm{~s}$ on the basis of the original schedule, there are 1010-1015 combinations of dwell time. The number of combinations is very large, too large to be enumerated; thus, an optimization algorithm is required for the solution. In a variety of heuristic algorithms, genetic algorithms operate directly on the structure of the object, with no derivation or function continuity limit, thus allowing the use of a very complex fitness function (also known as the target function), and the variable range of variables can be restricted. Randomization optimization methods can automatically obtain and guide the optimization search space and do no need to identify the rules; thus, they are more suitable for optimization in which time is the variable. Therefore, this paper uses a genetic algorithm to optimize the dwell time.

\subsection{Introduction of Genetic Algorithm}

A genetic algorithm is a random search algorithm, referencing biological natural selection and genetic mechanisms. Different from traditional algorithms, genetic algorithms search from a randomly-generated initial solution, and through the selection, crossover and mutation operations iterate step by step to produce new solutions. Each individual in a group is a solution, called chromosomes. The merits of chromosomes are evaluated by the fitness function. According to the fitness value, we select a certain number of outstanding individuals from the previous generation, to form the following group through crossover and mutation operations. After several generations of evolution, the algorithm converges to the optimal chromosome, i.e., the final solution of the problem.

\subsection{Optimization Method}

Different combinations of dwell time have different impacts on the energy consumption of the power supply system. By means of the genetic algorithm to encode each dwell time, the optimal combination of the dwell time can be solved. 
Assuming that the train headway and synchronization time of the uplink and downlink train are fixed at the same period, the train operation curves in the same direction are the same (i.e., the operation curves of the uplink trains are the same, and the operation curves of the downlink trains are the same), and the dwell times of the uplink and downlink trains at the same station are the same, as shown in Equation (19).

$$
\begin{aligned}
& t_{\text {down }}=\left\{t_{1}, t_{2}, \cdots t_{i} \cdots, t_{N-1}, t_{N}\right\} \\
& t_{\text {up }}=\left\{t_{N}, t_{N-1}, \cdots t_{i} \cdots, t_{2}, t_{1}\right\}
\end{aligned}
$$

where $N$ is the number of stations; $t_{i}$ is the dwell time of the $i$-th station; $t_{\text {down }}$ is the dwell time combination of downlink line; and $t_{u p}$ is the dwell time combination of the uplink line.

Based on the above assumptions, we can build a dwell time optimization model based on the genetic algorithm.

\subsubsection{Encoding}

The optimization parameter is the train dwell time; thus, the collection of the train dwell time at each station is encoded as a chromosome, and each station dwell time is the gene forming the chromosome. Using real numbers to encode the dwell time, the schematic diagram of dwell time encoding is shown in Figure 11.

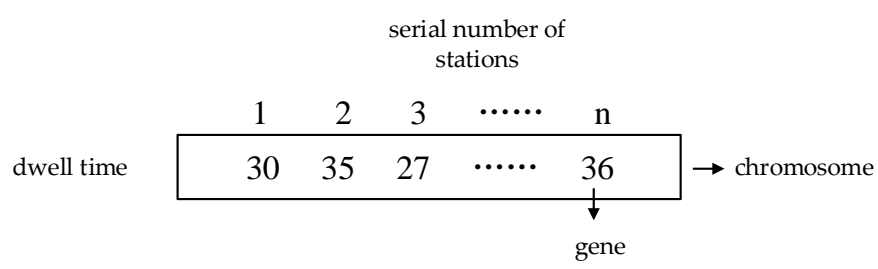

Figure 11. Schematic diagram of dwell time encoding.

In an urban rail transit system, the length of the train dwell time is related to the number of passengers, the number of train doors and other factors [45]. In order to ensure the boarding/alighting needs of passengers during actual operation, this paper optimizes the dwell time based on the existing train schedule in a certain range. Therefore, the encoding must restrain the size of the gene, e.g., the dwell time is required within $25-45 \mathrm{~s}$ for each station, or adjusted within $-5 \mathrm{~s}-+5 \mathrm{~s}$ on the basis of the original dwell time, to ensure the feasibility of the dwell time after optimization. Using the genetic algorithm, the initial population is generated, and for each chromosome, the genes must satisfy Equation (20).

$$
t_{\text {low_limt }} \leqslant t_{i} \leqslant t_{\text {up_limt }}
$$

where $t_{\text {up_limit }}$ is the upper limit of dwell time; and $t_{\text {low_limit }}$ is the lower limit of dwell time.

\subsubsection{Generating the Initial Population}

According to the genetic algorithm, the initial population of the combination of different dwell times is randomly generated, as shown in Figure 12. 


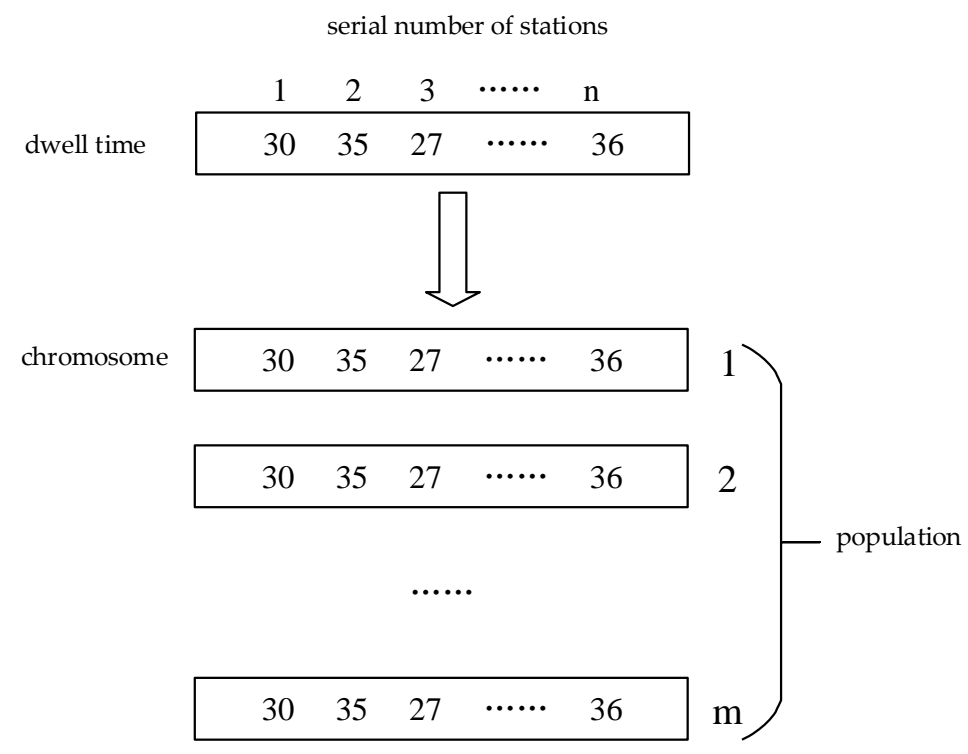

Figure 12. Initial population of dwell time.

\subsubsection{Fitness Function}

The optimization of the train dwell time affects the utilization of the regenerative braking energy when the multi-train is operating. The electric energy used by the train originates from the traction substation, thus the optimization objective function is the total energy consumption of the traction power supply system. The negative value of the energy consumption of the fitness function is shown in Equation (21).

$$
\text { Fit_function }=-\int_{0}^{T} P_{s} d t
$$

where $P_{s}$ is the total power of all substations; and $T$ is the total operation time.

\subsection{Calculation Flowchart}

Figure 13 is the algorithm flowchart of the train dwell time optimization using a genetic algorithm.

1. The first generation of the population is generated randomly, and the $m$ individuals generated correspond to the collection of dwell time, where $\mathrm{m}$ is the population quantity.

2. Combining the dwell time in Step 1 and train operation data, the input direct current supply model is used to establish the corresponding circuits to calculate the electric and energy consumption data of the trains and power substation.

3. According to the fitness function, Equation (20) is used calculate the fitness value of each individual.

4. According to the fitness value calculated in Step 3, we perform genetic manipulation, such as selection, cross, mutation, and so on, to generate a new population.

5. We determine whether the termination conditions are met, and if they are not satisfied, the new generation of population data will be input into Step 2 to continue the calculation; if they are satisfied, then the calculation and output results are terminated. 


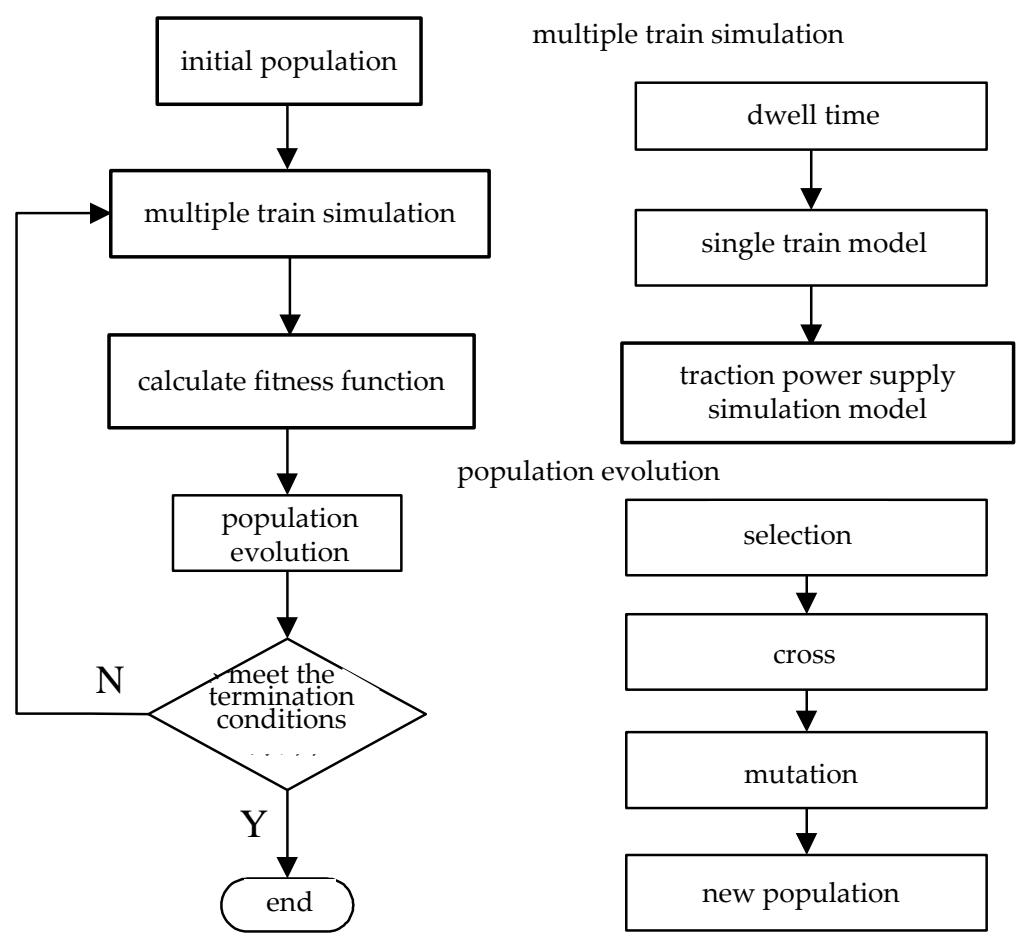

Figure 13. Flowchart of the dwell time optimization algorithm.

\section{Dwell Time Optimization Based on Yizhuang Subway Line}

The traction power supply system of the Beijing subway Yizhuang Line adopts the distributed power supply mode, with a total of 12 traction substations. The traction substation adopts the 24-pulse rectifier, as described in detail in Section 3.2.1. Regenerative braking absorbing resistors are set in each of the traction substation. Using the third rail power supply mode, the rated voltage is DC $750 \mathrm{~V}$.

The train equivalent mass of Beijing Yizhuang subway line with different load cases is listed in Table 1. In Table 1, AW represents the train passenger capacity. AW0 represents no passengers. AW2 represents rated passenger capacity. AW3 represents overload passenger capacity. M represents motor car, T represents trailer car and Tc represents trailer with a cab. AW3 is the normal operation condition of Beijing Yizhuang subway line. The simulation data are AW3 level. Train and line parameters are listed in Table 2. A single motor rated power is $180 \mathrm{~kW}$. There are four motors.

Table 1. Train equivalent mass of Beijing Yizhuang subway line with different load cases.

\begin{tabular}{ccccccc}
\hline Train Equivalent Mass (t) & Tc1 & M1 & T & M3 & M2 & Tc2 \\
\hline AW0 & 33 & 35 & 28 & 35 & 35 & 33 \\
AW2 & 46.56 & 50.24 & 43.24 & 50.24 & 50.24 & 46.56 \\
AW3 & 50.4 & 54.5 & 47.5 & 54.5 & 54.5 & 50.4 \\
\hline
\end{tabular}

Table 2. Train and line parameters.

\begin{tabular}{cccc}
\hline Parameters & Value & Parameters & Value \\
\hline Nominal voltage & $750 \mathrm{~V}$ & Efficiency of inverter & 0.93 \\
Maximum voltage & $900 \mathrm{~V}$ & Efficiency of motor & 0.915 \\
Minimum voltage & $680 \mathrm{~V}$ & Efficiency of gear & 0.975 \\
Power-factor of load & 0.85 & Motor rated power & $180 \mathrm{~kW} 4$ \\
Regeneration limit voltage U1/U2 & $900 \mathrm{~V} / 950 \mathrm{~V}$ & Maximum acceleration & $1 \mathrm{~m} / \mathrm{s}^{2}$ \\
Maximum speed & $80 \mathrm{~km} / \mathrm{h}$ & Maximum deceleration & $1 \mathrm{~m} / \mathrm{s}^{2}$ \\
Resistance of traction network & $50.007 \Omega / \mathrm{km}$ & Resistance of rail & $0.009 \Omega / \mathrm{km}$ \\
\hline
\end{tabular}


The Yizhuang subway line has a total of 14 stations. According to the current actual operating schedules, the dwell times of each station are listed in Table 3. The dwell time throughout the day of each train is the same, and the dwell time of the same station of up trains and down trains is the same.

Table 3. Dwell times of Yizhuang subway line.

\begin{tabular}{ccccc}
\hline $\begin{array}{c}\text { Serial } \\
\text { Number }\end{array}$ & Station Name & $\begin{array}{c}\text { Dwell } \\
\text { Time (s) }\end{array}$ & Station Name & $\begin{array}{c}\text { Dwell } \\
\text { Time (s) }\end{array}$ \\
\hline 1 & Songjiazhuang & $/$ & Yizhuang Railway Station & $/$ \\
2 & Xiaocun & 30 & Ciqu & 35 \\
3 & Xiaohongmen & 30 & Ciqu South & 35 \\
4 & Jiugong & 30 & Jinghailu & 30 \\
5 & Yizhuangqiao & 35 & Tongjinanlu & 30 \\
6 & Yizhuang Culture Park & 30 & Rongchandongjie & 30 \\
7 & Wanyuanjie & 30 & Rongjingdongjie & 30 \\
8 & Rongjingdongjie & 30 & Wanyuanjie & 30 \\
9 & Rongchandongjie & 30 & Yizhuang Culture Park & 30 \\
10 & Tongjinanlu & 30 & Yizhuangqiao & 35 \\
11 & Jinghailu & 30 & Jiugong & 30 \\
12 & Ciqu South & 35 & Xiaohongmen & 30 \\
13 & Ciqu & 35 & Xiaocun & 30 \\
14 & Yizhuang Railway Station & $/$ & Songiiazhuang & $/$ \\
\hline
\end{tabular}

Using the genetic algorithm to encode the 12 dwell times, the upper and lower bounds of the dwell time of each train are bound to the $-5-+10$ s range of the original stop time. In the simulation, the headway is $5.5 \mathrm{~min}$; the synchronization time of the up train and the down train is $3.5 \mathrm{~min}$; and the train operation data use automatic train operation (ATO) actual operation data. The genetic parameter settings are shown in Table 4. Figure 14 is an evolution of the search for the optimal solution in the algorithm calculation process.

Table 4. Simulation parameters.

\begin{tabular}{cc}
\hline Simulation Parameters & Value \\
\hline Population size & 40 \\
Maximum number of generations & 100 \\
Generation gap & 0.95 \\
Crossover probability & 0.7 \\
Mutation probability & 0.01 \\
\hline
\end{tabular}

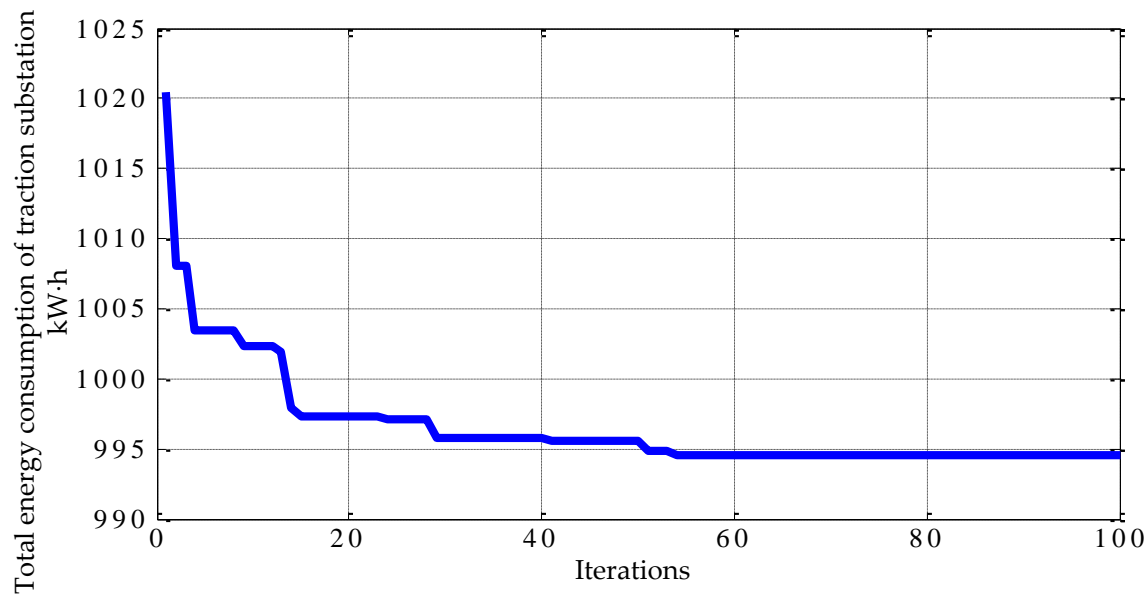

Figure 14. Evolution of searching for the optimal solution. 
Table 5 shows the constraint conditions of dwell time and the results of the dwell time optimization in the simulation. It can be seen that the dwell time after the optimization is only increased by $29 \mathrm{~s}$, while the whole running time of the Yizhuang Line is about 34 min; thus, the impact on the running time is minimal.

Table 5. Dwell time of Yizhuang subway line before and after optimization.

\begin{tabular}{|c|c|c|c|c|c|c|}
\hline \multirow{2}{*}{$\begin{array}{l}\text { Serial } \\
\text { Number }\end{array}$} & \multirow[b]{2}{*}{ Station Name } & \multirow{2}{*}{$\begin{array}{l}\text { Dwell } \\
\text { Time (s) }\end{array}$} & \multicolumn{2}{|c|}{ Optimization Scope (s) } & \multirow{2}{*}{$\begin{array}{c}\text { Post-Optimization } \\
\text { Time (s) }\end{array}$} & \multirow{2}{*}{$\begin{array}{c}\text { Difference before } \\
\text { and after } \\
\text { Optimization }\end{array}$} \\
\hline & & & $\begin{array}{l}\text { Lower } \\
\text { Limit }\end{array}$ & $\begin{array}{l}\text { Upper } \\
\text { Limit }\end{array}$ & & \\
\hline 1 & Songjiazhuang & / & / & / & / & / \\
\hline 2 & Xiaocun & 30 & 25 & 40 & 35 & 5 \\
\hline 3 & Xiaohongmen & 30 & 25 & 40 & 35 & 5 \\
\hline 4 & Jiugong & 30 & 25 & 40 & 32 & 2 \\
\hline 5 & Yizhuangqiao & 35 & 30 & 45 & 36 & 1 \\
\hline 6 & Yizhuang Culture Park & 30 & 25 & 40 & 34 & 4 \\
\hline 7 & Wanyuanjie & 30 & 25 & 40 & 35 & 5 \\
\hline 8 & Rongjingdongjie & 30 & 25 & 40 & 33 & 3 \\
\hline 9 & Rongchandongjie & 30 & 25 & 40 & 34 & 4 \\
\hline 10 & Tongjinanlu & 30 & 25 & 40 & 34 & 4 \\
\hline 11 & Jinghailu & 30 & 25 & 40 & 35 & 5 \\
\hline 12 & Ciqu South & 35 & 30 & 45 & 31 & -4 \\
\hline 13 & Ciqu & 35 & 30 & 45 & 30 & -5 \\
\hline \multirow[t]{2}{*}{14} & Yizhuang Railway Station & / & / & / & / & / \\
\hline & The total time & 375 & & & 404 & 29 \\
\hline
\end{tabular}

Table 6 shows the energy consumption changes before and after dwell time optimization. It can be seen that the system total energy consumption is decreased from 1084 down to $995 \mathrm{~kW} \cdot \mathrm{h}$, a decrease of $8 \%$; meanwhile, the utilization rate of regenerative braking is improved from $71 \%-79 \%$, for an improvement of $8 \%$. Based on the genetic algorithm, the dwell time optimization effect is significant; the total energy consumption is reduced; and the utilization rate of regenerative braking is improved.

Assuming that the train operation curve is unchanged in simulation, namely the train running time between stations is fixed, only the dwell time is optimized. As for the train, because the operation curve is the same, the train traction energy consumption and regenerative braking energy are the same before and after optimization. The fact that the energy consumption of the train traction and regenerative braking energy before and after optimization have a certain difference, as shown in Table 6 , is a result of the simulation results when compared to the multiple trains running results in fixed $15 \mathrm{~min}$; before and after optimization, the dwell time of the train changes; the input power of train operation is different in the same time.

Table 6. Energy consumption after dwell time optimization.

\begin{tabular}{cccc}
\hline Energy Consumption $\mathbf{( k W} \cdot \mathbf{h})$ & $\begin{array}{c}\text { Before } \\
\text { Optimization }\end{array}$ & $\begin{array}{c}\text { After } \\
\text { Optimization }\end{array}$ & $\begin{array}{c}\text { Rate of } \\
\text { Change }\end{array}$ \\
\hline Train traction energy consumption & 1674 & 1655 & \\
Train regenerative braking energy & 930 & 922 & \\
Substation total energy consumption & 1084 & 995 & $-8 \%$ \\
Braking resistance absorption energy & 270 & 195 & \\
The line losses energy & 70 & 67 & $8 \%$ \\
Utilization rate of regenerative braking & $71 \%$ & $79 \%$ & 8 \\
\hline
\end{tabular}

Figures 15 and 16 are the total output power of the traction substation and the absorption power of braking resistance before and after dwell time optimization, respectively. For the convenience of comparison, in the figure, the power curve is filled with color; the envelope curve is the power value; the area surrounded by the envelope is the value of energy consumption. The blue curve is the total power of the substation, and the red curve is the total power absorbed by the braking resistance, i.e., the regenerative braking energy cannot be used. By comparison, it is clear that the optimized substation 
output energy consumption value is smaller; the energy consumption in the simulation time is quite average; and the energy absorption of the braking resistors decreases significantly.

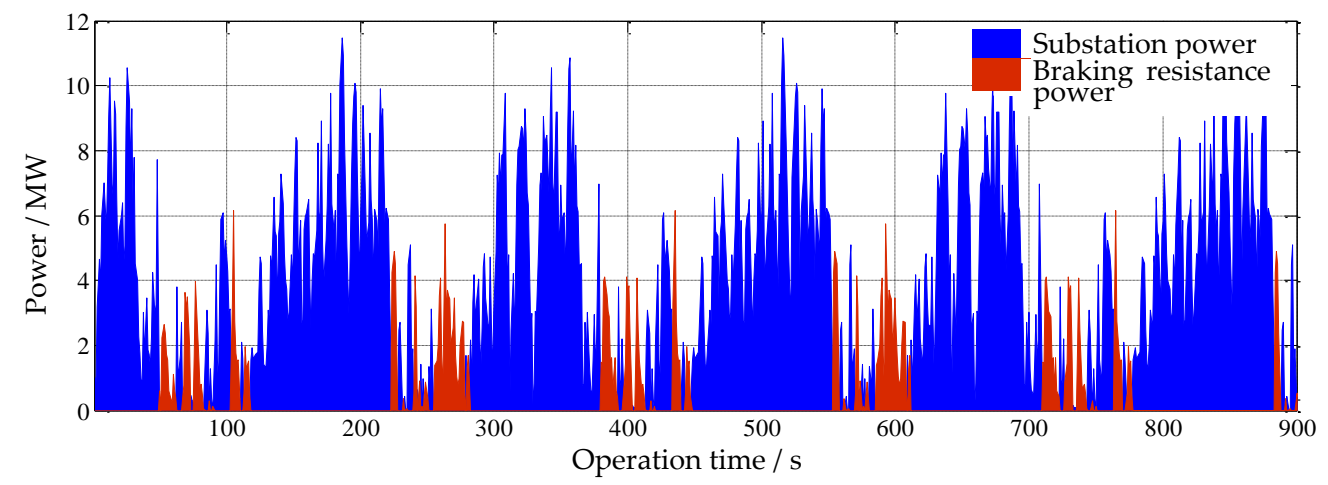

Figure 15. Total output power of traction substation and absorption power of braking resistance before dwell time optimization.

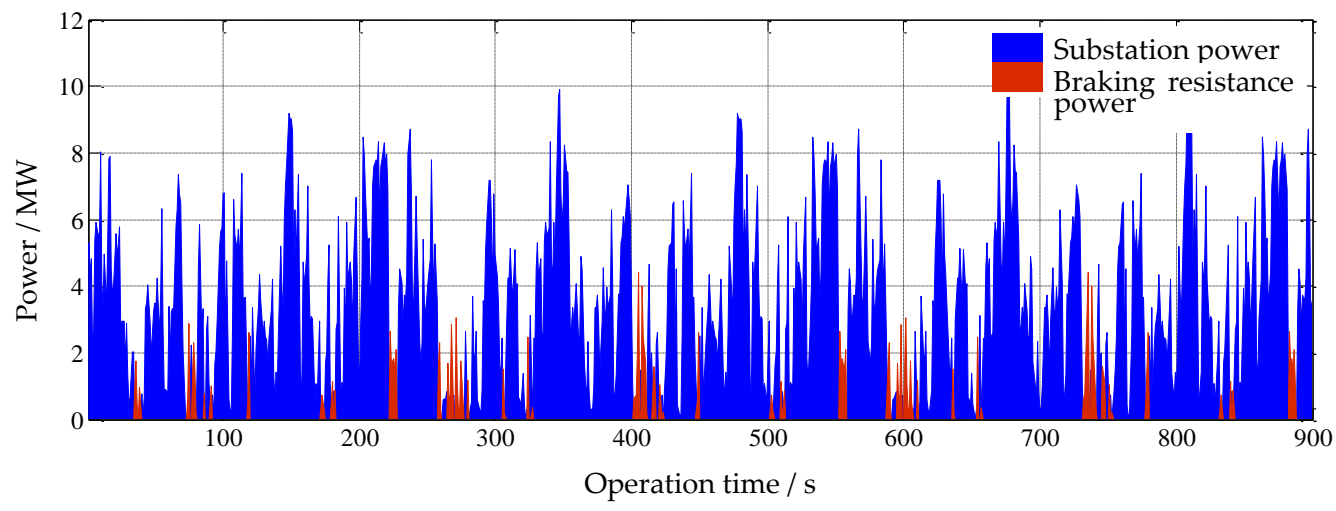

Figure 16. Total output power of traction substation and absorption power of braking resistance after dwell time optimization.

From the peak value of power, the peak value of the output power of the traction substation and absorption power of braking resistance are both decreased. After optimization, the peak value of the output power of the traction substation decreases from 11.5 down to $9.9 \mathrm{MW}$, for a decrease of $14 \%$; and the peak value of the absorption power of braking resistance is decreased from 6.2 down to 4.4 MW, for a decrease of $29 \%$.

Figure 17 is the energy consumption comparison chart of each substation before and after dwell time optimization. It can be seen that the energy consumptions of the Yizhuang Railway Station, Ciqu South, Jinghailu and Tongjinanlu substations change greatly, while those of Songiiazhuang and other stations do not change significantly or are increased. Taking Yizhuang Railway Station and Songjiazhuang as examples, the substation power and absorption power of braking resistance are analyzed. Figures 18 and 19 show the substation output power curve and braking resistance absorption power curve of Yizhuang Railway Station before and after dwell time optimization, respectively. For the convenience of comparison, the power curve before optimization is red, and that after optimization is blue. After the dwell time optimization, the substation traction power decreases obviously, and the absorption power of braking resistance also decreases; thus, the traction energy consumption values of the Yizhuang Railway Station substation decreased significantly. 


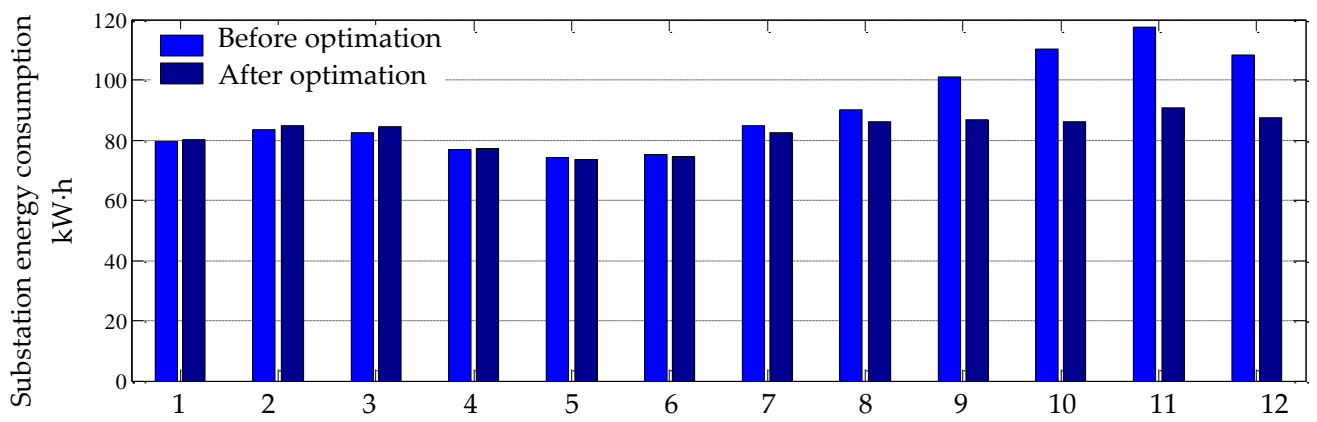

Figure 17. Energy consumption of each substation before and after dwell time optimization.

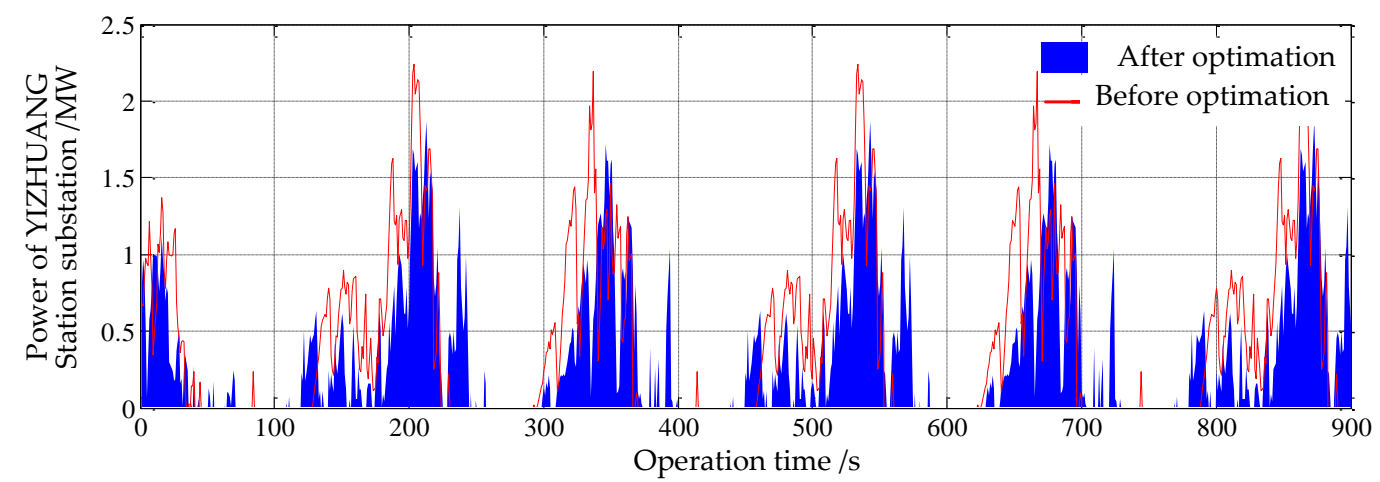

Figure 18. Power of Yizhuang Railway Station's substation before and after dwell time optimization.

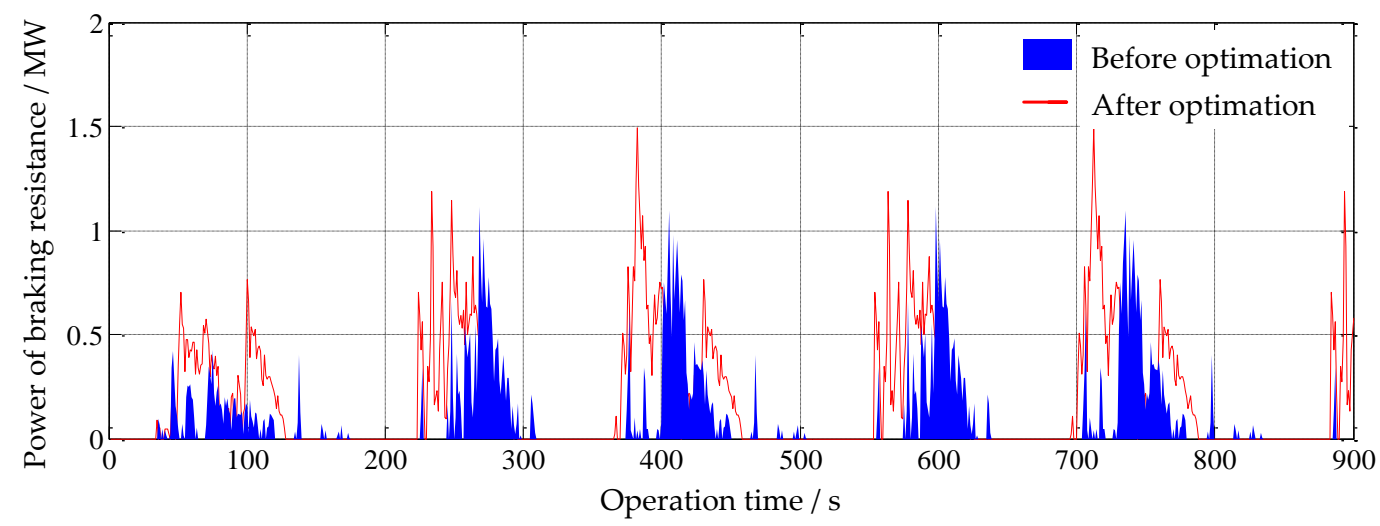

Figure 19. Power of Yizhuang Railway Station's braking resistance before and after dwell time optimization.

Figures 20 and 21 respectively show the substation output power curve and braking resistance absorption power curve of Songjiazhuang before and after dwell time optimization. It can be seen that the substation power and absorption power of the braking resistance are not significantly reduced nor increased at Songjiazhuang before and after the optimization; thus, the change of the power consumption of the substation at Songiiazhuang is minimal. 


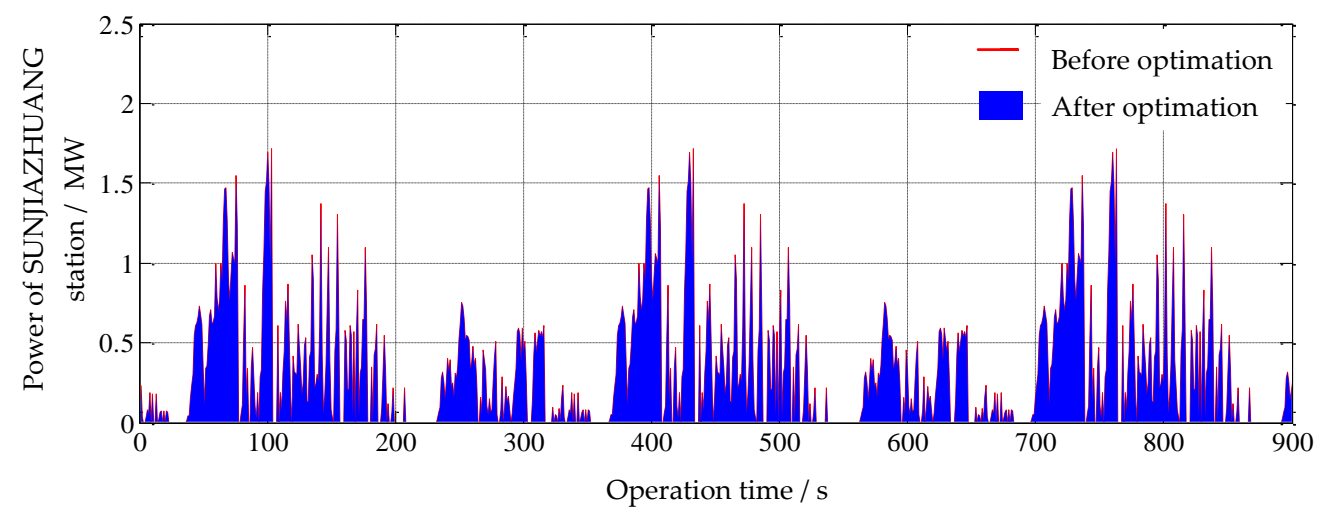

Figure 20. Power of Songjiazhuang's substation before and after dwell time optimization.

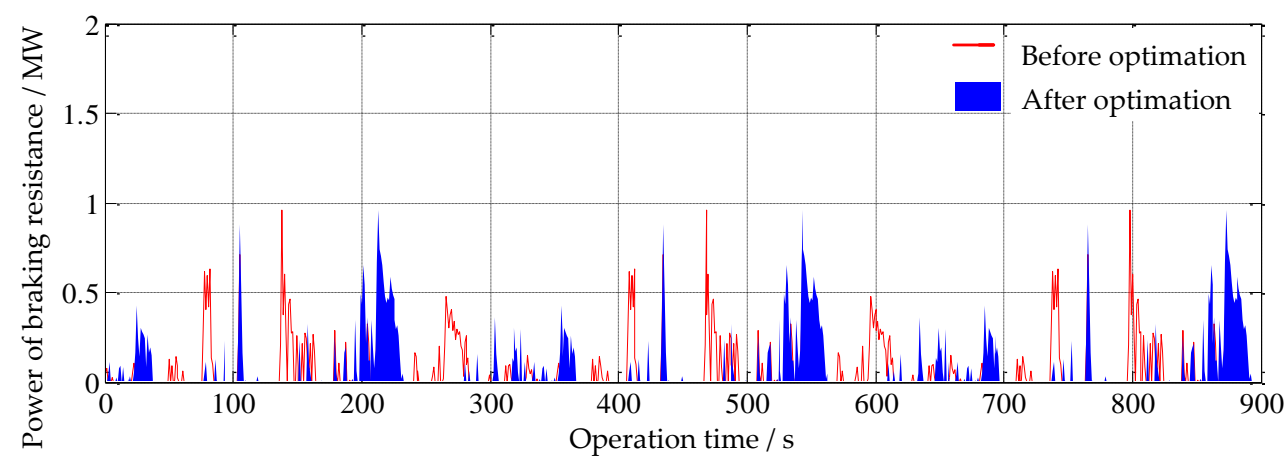

Figure 21. Power of Songjiazhuang's braking resistance before and after dwell time optimization.

\section{Conclusions}

In this paper, the basic principles of train energy saving optimization based on dwell time are introduced, and the optimization model based on dwell time is established. With the system total energy consumption minimum as the objective function and based on the multi-train operation model and power system simulation model, while using a genetic algorithm, the optimization model of the dwell time is solved. In addition, taking the Yizhuang Line as an example, based on the Yizhuang Line current dwell time and under the condition of the train running time increasing by $29 \mathrm{~s}$, the regenerative braking rate of the system is increased by $8 \%$, and the total traction energy consumption is reduced by $8 \%$; thus, the total traction energy consumption is reduced by $8 \%$. The results show that using this method is practical and effective.

Acknowledgments: This research is supported by the National Natural Science Foundation of China under Grant 5157701.

Author Contributions: Fei Lin contributed to the conception of the study and the algorithm. Shihui Liu, Zhihong Yang and Yingying Zhao contributed significantly to the analysis and manuscript preparation. Zhongping Yang helped to perform the analysis with constructive discussions. Hu Sun provided the line and vehicle data.

Conflicts of Interest: The authors declare no conflict of interest.

\section{References}

1. Barrero, R.; Van Mierlo, J.; Tackoen, X. Energy savings in public transport. IEEE Veh. Technol. Mag. 2008, 3, 26-36. [CrossRef]

2. Beijing Subway. Available online: http://www.bjsubway.com/news/qyxw/yyzd/2016-01-04/42043.html (accessed on 25 June 2016). 
3. González-Gil, A.; Palacin, R.; Batty, P.; Powell, J. A systems approach to reduce urban rail energy consumption. Energy Convers. Manag. 2014, 80, 509-524. [CrossRef]

4. Chevrier, R. An evolutionary multi-objective approach for speed tuning optimization with energy saving in railway management. In Proceedings of the 13th IEEE International Conference on Intelligent Transportation Systems, Funchal, Portugal, 19-22 September 2010; pp. 279-284.

5. Chevrier, R.; Pellegrini, P.; Rodriguez, J. Energy saving in railway timetabling: A bi-objective evolutionary approach for computing alternative running times. Transp. Res. C Emerg. Technol. 2013, 37, 20-41. [CrossRef]

6. Bocharnikov, Y.; Tobias, A.; Roberts, C.; Hillmansen, S.; Goodman, C. Optimal driving strategy for traction energy saving on DC suburban railways. IET Electr. Power Appl. 2007, 1, 675-682. [CrossRef]

7. Domínguez, M.; Fernández-Cardador, A.; Cucala, A.P.; Gonsalves, T.; Fernández, A. Multi objective particle swarm optimization algorithm for the design of efficient ATO speed profiles in metro lines. Eng. Appl. Artif. Intell. 2014, 29, 43-53. [CrossRef]

8. Domínguez, M.; Fernández-Cardador, A.; Cucala, A.P.; Pecharromán, R.R. Energy savings in metropolitan railway substations through regenerative energy recovery and optimal design of ato speed profiles. IEEE Trans. Autom. Sci. Eng. 2012, 9, 496-504. [CrossRef]

9. Domínguez, M.; Fernández, A.; Cucala, A.; Lukaszewicz, P. Optimal design of metro automatic train operation speed profiles for reducing energy consumption. Proc. Inst. Mech. Eng. F J. Rail Rapid Transit 2011, 225, 463-474. [CrossRef]

10. Adinolfi, A.; Lamedica, R.; Modesto, C.; Prudenzi, A.; Vimercati, S. Experimental assessment of energy saving due to trains regenerative braking in an electrified subway line. IEEE Trans. Power Deliv. 1998, 13, 1536-1542. [CrossRef]

11. Liu, H.; Jiang, J. Flywheel energy storage-An upswing technology for energy sustainability. Energy Build. 2007, 39, 599-604. [CrossRef]

12. Suzuki, Y.; Koyanagi, A.; Kobayashi, M.; Shimada, R. Novel applications of the flywheel energy storage system. Energy 2005, 30, 2128-2143. [CrossRef]

13. Tzeng, J.; Emerson, R.; Moy, P. Composite flywheels for energy storage. Compos. Sci. Technol. 2006, 66, 2520-2527. [CrossRef]

14. Bolund, B.; Bernhoff, H.; Leijon, M. Flywheel energy and power storage systems. Renew. Sustain. Energy Rev. 2007, 11, 235-258. [CrossRef]

15. Wang, G.; Zhang, L.; Zhang, J. A review of electrode materials for electrochemical supercapacitors. Chem. Soc. Rev. 2012, 41, 797-828. [CrossRef] [PubMed]

16. Burke, A.; Miller, M. The power capability of ultracapacitors and lithium batteries for electric and hybrid vehicle applications. J. Power Sources 2011, 196, 514-522. [CrossRef]

17. Hammar, A.; Venet, P.; Lallemand, R.; Coquery, G.; Rojat, G. Study of accelerated aging of supercapacitors for transport applications. IEEE Trans. Ind. Electron. 2010, 57, 3972-3979. [CrossRef]

18. Sharma, P.; Bhatti, T.S. A review on electrochemical double-layer capacitors. Energy Convers. Manag. 2010, 51, 2901-2912. [CrossRef]

19. Iannuzzi, D.; Tricoli, P. Metro trains equipped onboard with supercapacitors: A control technique for energy saving. In Proceedings of the IEEE International Symposium on Power Electronics Electrical Drives Automation and Motion (SPEEDAM), Pisa, Italy, 14-16 June 2010; pp. 750-756.

20. Wang, B.; Yang, Z.; Lin, F.; Zhao, W. An Improved Genetic Algorithm for Optimal Stationary Energy Storage System Locating and Sizing. Energies 2014, 7, 6434-6458. [CrossRef]

21. Xia, H.; Chen, H.; Yang, Z.; Lin, F.; Wang, B. Optimal Energy Management, Location and Size for Stationary Energy Storage System in a Metro Line Based on Genetic Algorithm. Energies 2015, 8, 11618-11640. [CrossRef]

22. Kraytsberg, A.; Ein-Eli, Y. Review on Li-air batteries-Opportunities, limitations and perspective. J. Power Sources 2011, 196, 886-893. [CrossRef]

23. Ellis, B.L.; Nazar, L.F. Sodium and sodium-ion energy storage batteries. Curr. Opin. Solid State Mater. Sci. 2012, 16, 168-177. [CrossRef]

24. Mukherjee, R.; Krishnan, R.; Lu, T.M.; Koratkar, N. Nanostructured electrodes for high-power lithium ion batteries. Nano Energy 2012, 1, 518-533. [CrossRef]

25. Czerwiński, A.; Obrębowski, S.; Rogulski, Z. New high-energy lead-acid battery with reticulated vitreous carbon as a carrier and current collector. J. Power Sources 2012, 198, 378-382. [CrossRef] 
26. Chen, J.F.; Lin, R.L.; Liu, Y.C. Optimization of an mrt train schedule: Reducing maximum traction power by using genetic algorithms. IEEE Trans. Power Syst. 2005, 20, 1366-1372. [CrossRef]

27. Kim, K.M.; Oh, S.M. A model and approaches for smoothing peaks of traction energy in timetabling. J. Korean Soc. Railw. 2009, 12, 1018-1023.

28. Kim, K.M.; Oh, S.M.; Han, M. A mathematical approach for reducing the maximum traction energy: The case of Korean MRT trains. In Proceedings of the International MultiConference of Engineers and Computer Scientists, Hong Kong, China, 17-19 March 2010; pp. 2169-2173.

29. Gordon, S.P.; Lehrer, D.G. Coordinated train control and energy management control strategies. In Proceedings of the 1998 ASME/IEEE Joint Railroad Conference, Philadelphia, PA, USA, 15-16 April 1998; pp. 165-176.

30. Galán, A.R.; Alcaraz, M.T.P.; Morales, A.F.; Cucala, P. Mathematical Programming Approach to Underground Timetabling Problem for Maximizing Time Synchronization; XI Congreso de Ingeniería de Organización: Madrid, Italy; 5-7; September; 2007; pp. 1395-1405.

31. Yang, X.; Ning, B.; Li, X.; Tang, T. A two-objective timetable optimization model in subway systems. IEEE Trans. Intel-Light Transp. Syst. 2014, 15, 1-9. [CrossRef]

32. Zhao, L.; Li, K.; Su, S. A Multi-objective Timetable Optimization Model for Subway Systems. EITRT2013 2014, 1, 557-565.

33. Nasri, A.; Moghadam, M.F.; Mokhtari, H. Timetable optimization for maximum usage of regenerative energy of braking in electrical railway systems. In Proceedings of IEEE International Symposium on Power Electronics Electrical Drives Automation and Motion (SPEEDAM), Pisa, Italy, 14-16 June 2010; pp. 1218-1221.

34. Albrecht, T.; Oettich, S. A new integrated approach to dynamic schedule synchronization and energy-saving train control. In Computers in Railways VIII; WIT Press: Southampton, UK, 2002; pp. 847-856.

35. Albrecht, T. Reducing power peaks and energy consumption in rail transit systems by simultaneous train running time control. In Computers in Railways IX; WIT Press: Southampton, UK, 2004; pp. 885-894.

36. Gong, C.; Zhang, S.; Zhang, F.; Jiang, J.; Wang, X. An integrated energy-efficient operation methodology for metro systems based on a real case of Shanghai metro line one. Energies 2014, 7, 7305-7329. [CrossRef]

37. Su, S.; Li, X.; Tang, T. A subway train timetable optimization approach based on energy-efficient operation strategy. IEEE Trans. Intel-Light Transp. Syst. 2013, 14, 883-893. [CrossRef]

38. Su, S.; Tang, T.; Li, X.; Gao, Z. Optimization of multi-train operations in a subway system. IEEE Trans. Intell. Transp. Syst. 2014, 15, 673-684.

39. Miyatake, M.; Matsuda, K. Energy Saving Speed and Charge/Discharge Control of a Railway Vehicle with On-board Energy Storage by Means of an Optimization Model. IEEJ Trans. Electr. Electron. Eng. 2009, 4, 771-778. [CrossRef]

40. Guo, D. Research on the Solution of Simulation for Urban Traction Power Including Regenerative Braking. Master's Thesis, Southwest Jiaotong University, Chengdu, China, 2005.

41. Liu, W.; Li, Q.; Li, L. Steady-state short-circuit salculation of DC traction supply system based on polygonal external characteristic. Electr. Drive Locomot. 2008, 1, 61-64.

42. Shen, N. Model of Inverter for Regenarative Energy Feedback and Process Simulation in DC Traction Power Supply System. Master's Thesis, Southwest Jiaotong University, Chengdu, China, 2009.

43. Liu, X.; Yu, S.; Liu, X. Model and algorithm for traction power system simulation of urban rail-line. Comput. Simul. 2004, 12, 213-218.

44. Liu, W.; Li, Q.; Chen, M. Study of unified AC/DC power flow in DC traction power supply system. Power Syst. Prot. Control 2010, 38, 128-133.

45. Zheng, L.; Song, R.; Wei, H.S.; Dong, L.H. Optimization Model and Algorithm of Skip-stop Strategy for Urban Rail Transit. J. China Railw. Soc. 2009, 31, 1-8.

(C) 2016 by the authors; licensee MDPI, Basel, Switzerland. This article is an open access article distributed under the terms and conditions of the Creative Commons by Attribution (CC-BY) license (http://creativecommons.org/licenses/by/4.0/). 